\title{
Success Factors Affecting Public Projects of Construction Industry in Pakistan
}

\author{
Sardar Ahsen ${ }^{1}$, Dr. Nafees Ahmed Memon ${ }^{2}$, Aftab Hameed Memon ${ }^{3}$, Noman Ahmed ${ }^{4}$ \\ ${ }^{1}$ Research Scholar, Department of Civil Engineering, Mehran University of Engineering and Technology, \\ Jamshoro, Pakistan, sardar.ahsen93@gmail.com \\ ${ }^{2}$ Professor, Department of Civil Engineering, Mehran University of Engineering and Technology, Jamshoro, \\ Pakistan, nafees.memon@gmail.com \\ ${ }^{3}$ Associate Professor, Department of Civil Engineering, Quaid-e-Awam University of Engineering, Sciences and \\ Technology Nawabshah, Pakistan, aftab@quest.edu.pk \\ ${ }^{4}$ Research Scholar, Department of Civil Engineering, Mehran University of Engineering and Technology, \\ Jamshoro, Pakistan, nauman.ahmed1994@outlook.com
}

Received Date : September 04, 2021 Accepted Date : September 25, 2021 Published Date : October 07, 2021

\begin{abstract}
The global enhancement in the construction of megaprojects during the last few decades has triggered competition in project management. Achieving successful completion of projects is the fundamental need that requires understanding the critical factors that govern the productive accomplishment of tasks within due time and budget, simultaneously maintaining the quality and safety standards. Besides, the cost, time and quality, health\& safety and environmental issues, and efficient project use are equally important factors that need special consideration to complete a project successfully. Several projects have demonstrated different barriers, especially in construction projects in the public sector in developing countries, such as Pakistan. Hence, this study investigated the criteria considered by the practitioners for measuring success in the construction project of Pakistan. A questionnaire survey involved 43 construction practitioners identifying the indicators relevant to measuring the success of Pakistani construction projects. The findings obtained through Statistical analysis (SPSS) and MS Excel revealed that the most common success factors of construction projects are the role of government, client capability, and project management. From a significance point of view, the role of government is reported as the most significant success factor. The government requires to exercise strict policy for getting work done successfully.
\end{abstract}

Key words: success factor, construction, Pakistan, public projects

\section{INTRODUCTION}

The construction sector governs any country's economy and is considered an indicator of a nation's financial well-being.
Therefore, construction projects are tangible pathways to boost the construction sector. Construction projects include unrepeatable activities with several exclusive characteristics, such as time limitations, complex procedures, tremendously challenging situations, financial capabilities, and vibrant organization arrangements [1]-[2]. The overall successful completion of a project involves various stakeholders' efforts and expertise, including clients, consultants, contractors, and material and labor suppliers [3].

Due to increasing competition in the construction industry, the clients need a rapid and quality-based project completion to utilize their space and budget more quickly and effectively. Thus, the excellence of a construction project is proportional to the client's satisfaction, whereas successful completion is dependent on teamwork [4]. The construction industry provides the second largest employment opportunities in third-world countries [5], and minor changes in the completion trend of projects may affect the national economy. Like several other developing countries, the construction industry of Pakistan incorporates a vital contribution to the development of the country's economy. More than 35\% employed people in Pakistan are connected with the construction industry [6]. Hence, in the arena of the construction industry, it is emphasized that the critical factors for the successful completion of a project must be identified and utilized optimally. Though the list of essential factors of success is quite long, and ambiguity exists to categorize them as more important or not compared with each other, several factors can be classified as essential or critical success factors [7]-[8].

Unfortunately, the internal contradiction, vagueness, and inconsistency raise complicated problems for management to complete the project with the required quality and within the allocated budget. Recently, the economy of Pakistan has been improved by the contribution of housing and infrastructure development. However, a great flaw in fulfilling the 
agreed-upon time of projects has been observed. Several projects were completed; however, the stakeholders suffered an unexpected loss of money due to significant delay in completion and cost overrun [9]-[10]. In general, the major reason for this failure is the lack of understanding of the mandatory factors for a successful public sector project. There is a need to identify the role of success factors for the successful completion and the influence of success factors on the overall quality of the project [10]. In the above mentioned context, this study is aimed to explore and model the factors influencing project success in the construction industry of Pakistan.

This study will help determine how public sector infrastructure projects in Pakistan are judged to be successful and how the success factors contribute to success. In addition, this study will help practitioners and stakeholders involved in public sector construction projects to identify and overcome various types of problems that cause delays in the completion of tasks or lead to the failure of projects.

\section{LITERATURE REVIEW}

The term 'critical success factors' was first introduced by [7] while investigating the role of project management in the information system and declared that cost, time, and quality govern a construction project's progress. Later, [8] claimed that the definition of critical success factors varies from project to project and is based on the criteria set to understand the term 'successful project'. [11] defined the essential factors of success for a construction project primarily capture the project's progress from the root level. Their effects can be observed when the project reaches at least the mid-completion stage. [12] extended this definition by further adding the statement that critical factors are the factors that should be planned at the client level and executed with proper attention by the consultant and contractors efficiently at all stages of the project to achieve the expected outcome.

Several researchers have to contribute to identifying and defining success factors. [13] performed research evaluating seventy-five construction projects and revealed that decreasing profit margin, developed guidelines and strict following, increased meetings among stakeholders, and efficient control of commodities result in high quality resultant. Almost similar results were obtained in their study by [14]. Their investigation highlighted that cost, quality and scheduling have more impact on successful completion on the project. A study of more than 100 projects in the last decade concluded that there are nine other factors that contribute to the success of a construction project [15]. These factors include time, cost, quality, contingency planning, avoiding non-excusable delays, proper training to stakeholders about utilizing their resources efficiently, proper communication among stakeholders, hiring of experienced and well-known consultants and contractors, sufficient knowledge of risk management, maintenance of risk management register, sufficient and maintained documentation, and quick progress in one-third duration of the process. [16] admitted that cost, time, and quality are the most critical success factors; however, the realization of social responsibility significantly reduces the chances of delay in project and project failure. Notably, the management's role in coordinating with other stakeholders by understanding their nature and organizational setup leads towards completing a construction project.

[17] considers the post-constructional phenomenon as a part of successful project completion and declares that the client-contractor coordination and cost are the major factors that control the overall performance of a construction project. [18] collected data through survey questionnaires from experienced personal related to the construction industry and analyzed the survey form. Critical analysis revealed that clean bidding, socio-political atmosphere, equal opportunity policy, organizational setup ratio, and government writ highly influence a construction project's progress. However, their study was limited to the local public sector construction industry of China.

[19] investigated the effective level of success factors based on various attributes. Data was collected through seventy-eight survey questionnaires, and analysis of output was performed. The findings revealed that technical and environmental project complexities have negative impacts on safety performance and the negative impact of project complexity on safety performance becomes less significant when a higher level of resilient safety culture exists. Still, this impact might not be substantial for a high resilient safety culture level. Their study was limited to the Vietnam construction industry only. A comprehensive review of literature helped in listing 44 common factors used to measure the success of construction projects categorized into six categories.

\section{$>$ Government-related factors}

This construct includes items that are under the discretionary power of government. For any public project to be successful, it is mandatory to have the legal and political support of the government. Besides that, the relationship with local authorities for approvals and their involvement plays a vital role in completing the project. Moreover, minimizing the political conflicts and the government's financial guarantee adds value to the project outcomes.

\section{$>$ Market related/social factors}

Good social support acts as the key pillar for the successful completion of the public project. It is funded by public money, so it is mandatory to satisfy the general needs to gain confidence in the projects. Besides that, stable macroeconomics of the country and precise evaluation of the market and the competitors makes it easy for the cash flows/finances of the project to avoid any delays. 
Sardar Ahsen et al., International Journal of Emerging Trends in Engineering Research, 9(10), October 2021, 1321 - 1326

Client related factors

Clear vision and precise formulation of the client strategies make the project scope more vivid and increase the client's efficiency. Further to that, the client's involvement in the project and timely decision-making avoid change orders and reduce delays to increase the project's schedule performance and cost efficiency.

\section{Project management related factors}

Management commitment has always been the key factor for successful completion of the project. Project management factors act as the binding forces to keep the project on track. This includes the managers leadership skills, his communication and coordination system. Efficient supply chain management of material and human resource management reduces the project delays and adds value to the project's schedule efficiency. In addition to that, reliable and vivid contractual arrangements lessen the chances of conflict and arbitration for efficacious completion of the project.

\section{Contractor related factors}

One of the significant factors for the unsuccessful completion of the public project is the contractor's wrong selection. Contractor's experience and market reputation is the critical factor for the selection of the contractor. As it is usual practice in Pakistan, there is a delay in payment to the contractor due to the complex documentation process. Hence, the contractor's financial strength matters a lot to keep the work in progress to avoid delays. Besides that, due to the complex nature of the projects, the contractor must have access to latest equipment and machinery and to some extent, small processes can be automated.

\section{Project-related factors}

This construct includes all the items related to the project starting from proper selection of the project type to project delivery system. To successfully complete the public project, it is necessary to have financial transparency, a fair bidding process, and economical design. Besides that, the project monitoring and control system and proper site management add value to the project outcomes. Efficient planning and adequate risk analysis avoid delays to add value to the schedule efficiency of the project.

\section{DATA COLLECTION AND ANALYSIS}

This study involved a questionnaire survey in collecting the data. The collected data could be analyzed through different computer applications. This study utilized the IBM SPSS (Statistical Package for Social Sciences) and MS Excel to analyze the results. The Average Index (AI) method was used for descriptive analysis to rank the parameters. This method illustrates the findings in the rating of Likert (ordinal) scale categories. For this study, five-pint Likert scale was used as in table 1.
Table 1: Attributes of Cleveland dataset

\begin{tabular}{|c|c|c|}
\hline $\begin{array}{c}\text { Scal } \\
\text { e }\end{array}$ & Description & Abbreviation \\
\hline 1 & Not Relevant & NR \\
\hline 2 & Slightly Relevant & SR \\
\hline 3 & Moderately Relevant & M R \\
\hline 4 & Very Relevant & VR \\
\hline 5 & Extremely Relevant & ER \\
\hline
\end{tabular}

Collected data was analyzed for calculating Average Index (AI) value with following equation:

Average Index $=\left[\frac{\sum_{i=1}^{5} a_{i} x_{i}}{5 \sum_{i=1}^{5} X_{i}}\right]$ for five scale rating

Where,

$i=$ the rank

$\mathrm{a}_{\mathrm{i}}=$ constant of weightage assigned to $i$

$X_{i}=$ variable showing the frequency of the reply for the value of $i(1,2,3 \ldots)$

$X_{1}=$ occurrence of the 'Not Relevant' reply; equivalent to $a_{1}=$ 1 ;

$\mathrm{X}_{2}=$ occurrence of the 'Slightly Relevant' reply; equivalent to $\mathrm{a}_{2}=2$;

$\mathrm{X}_{3}=$ occurrence of the 'Moderately Relevant' reply; equivalent to $\mathrm{a}_{3}=3$;

$\mathrm{X}_{4}=$ occurrence of the 'Very Relevant' reply and equivalent to $\mathrm{a}_{4}=4$; and

$\mathrm{X}_{5}=$ occurrence of the 'Extremely Relevant' reply; equivalent to $\mathrm{a}_{5}=5$.

\subsection{Demography of Respondents}

A total of 80 questionnaire forms were distributed amongst the experienced practitioners involved in handling construction projects. Unfortunately, only 51 forms were received back, among which 43 were valid samples and used for analysis. Therefore, the factual information of the respondents participating in the questionnaire survey is presented in table 2 .

Table 2: Respondents' profile statistics

\begin{tabular}{|c|c|c|}
\hline Parameter & Frequency & Percent \\
\hline \multicolumn{3}{|l|}{ Type of Organization } \\
\hline Consultant & 14 & 32.5 \\
\hline Contractor & 5 & 11.6 \\
\hline Client & 23 & 53.5 \\
\hline Researcher/Academia & 1 & 2.4 \\
\hline Total & 43 & 100.0 \\
\hline \multicolumn{3}{|l|}{ Experience of Respondents } \\
\hline
\end{tabular}


Sardar Ahsen et al., International Journal of Emerging Trends in Engineering Research, 9(10), October 2021, 1321 - 1326

\begin{tabular}{|c|c|c|}
\hline $0-5$ years & 2 & 4.6 \\
\hline $6-10$ years & 6 & 13.9 \\
\hline $11-15$ Years & 11 & 25.7 \\
\hline $16-20$ years & 23 & 53.5 \\
\hline $21-25$ years & 0 & 0 \\
\hline Above 25 years & 1 & 2.3 \\
\hline Total & $\mathbf{4 3}$ & $\mathbf{1 0 0 . 0}$ \\
\hline
\end{tabular}

Researcher/Academia. Among these, 35 respondents have been working in the construction industry for more than ten years, and only eight respondents have experience of fewer than ten years.

\section{RESULTS AND DISCUSSION}

\subsection{Ranking of the Success Factors and Attributes}

The factor and the attributes are ranked based on the average index value of the factors and relative attributes. The frequency of response and ranking of the success factors is presented in table 3 .

Table 2 shows that most of the respondents, i.e., 23 are clients, 14 are consultants, 5 are contractors, and 1 is

Table 3: Ranking of Success Factors

\begin{tabular}{|c|c|c|c|c|c|c|c|c|c|}
\hline \multirow[b]{2}{*}{ No. } & \multirow{2}{*}{ Success Factors } & NR & SR & MR & VR & ER & \multirow{2}{*}{ Total } & \multirow{2}{*}{ AI } & \multirow{2}{*}{ Rank } \\
\hline & & 1 & 2 & 3 & 4 & 5 & & & \\
\hline 1 & Role of Government & 0 & 0 & 0 & 4 & 6 & 10 & 4.6 & 1 \\
\hline 3 & Client Capability & 0 & 0 & 0 & 5 & 5 & 10 & 4.5 & 2 \\
\hline 4 & Project Management & 0 & 0 & 2 & 0 & 8 & 10 & 4.0 & 3 \\
\hline 5 & Contractor Capability & 0 & 0 & 2 & 3 & 5 & 10 & 3.7 & 4 \\
\hline 6 & Project Conditions & 0 & 0 & 2 & 6 & 2 & 10 & 3.4 & 5 \\
\hline 7 & Market Conditions & 0 & 0 & 3 & 4 & 3 & 10 & 3.1 & 6 \\
\hline
\end{tabular}

quality of work. Similarly, project management is the third

From table 3, it is seen that role of the Government is the most relevant factor which plays a vital role in the success of public projects. The respondents placed client capability at the second rank in playing a role for achieving success in the projects. If the client is not capable or does not have adequate technical knowledge, it can also lead to disputes or affect the major factor of success. Project management is always considered an essential criterion in managing the projects from the conceptualization stage to the completion of the project. The frequency of response and the ranking of the attributes measuring the success factors is presented in table 4.

Table 4: Success Factors and Attributes

\begin{tabular}{|c|c|c|c|c|c|c|c|c|}
\hline \multirow{2}{*}{ No. } & \multirow{2}{*}{ Success Factors and Attributes } & NR & SR & MR & VR & ER & \multirow{2}{*}{ Total } & \multirow{2}{*}{ AI } \\
\hline & & 1 & 2 & 3 & 4 & 5 & & \\
\hline & \multicolumn{8}{|l|}{ Role of Government } \\
\hline 1 & Government approvals and involvement & 0 & 0 & 0 & 6 & 4 & 10 & 4.4 \\
\hline 2 & Government guarantee and experience & 0 & 1 & 2 & 2 & 5 & 10 & 3.8 \\
\hline 3 & Favorable legal and political support & 1 & 0 & 2 & 1 & 6 & 10 & 3.5 \\
\hline 4 & Good relationship with local bodies & 0 & 0 & 4 & 2 & 4 & 10 & 2.8 \\
\hline 5 & Political conflicts & 2 & 1 & 3 & 3 & 1 & 10 & 2.4 \\
\hline \multirow[t]{2}{*}{6} & Unethical practices & 3 & 1 & 5 & 0 & 1 & 10 & 1.3 \\
\hline & \multicolumn{8}{|l|}{ Market Conditions } \\
\hline 7 & Accurate analysis of market and competition & 0 & 0 & 1 & 3 & 6 & 10 & 4.2 \\
\hline 8 & Stable macro-economic conditions & 1 & 0 & 1 & 5 & 3 & 10 & 3.6 \\
\hline 9 & Market demand & 2 & 1 & 0 & 6 & 1 & 10 & 3.6 \\
\hline 10 & Purchasing power of the market & 0 & 0 & 2 & 5 & 3 & 10 & 3.5 \\
\hline \multirow[t]{2}{*}{11} & Favorable social support & 1 & 1 & 4 & 3 & 1 & 10 & 2.3 \\
\hline & \multicolumn{8}{|l|}{ Client Capability } \\
\hline 12 & Timely release of funds to contractor & 0 & 0 & 0 & 1 & 9 & 10 & 4.9 \\
\hline 13 & Design quality & 0 & 0 & 0 & 3 & 7 & 10 & 4.7 \\
\hline 14 & Effective project briefing & 0 & 0 & 0 & 6 & 4 & 10 & 4.4 \\
\hline 15 & Client involvement in the project & 0 & 0 & 0 & 8 & 2 & 10 & 4.2 \\
\hline
\end{tabular}


Sardar Ahsen et al., International Journal of Emerging Trends in Engineering Research, 9(10), October 2021, 1321 - 1326

\begin{tabular}{|c|c|c|c|c|c|c|c|c|}
\hline 16 & Client's decision making Skills & 0 & 0 & 2 & 1 & 7 & 10 & 3.9 \\
\hline 17 & Transparency in tendering process & 0 & 0 & 2 & 1 & 7 & 10 & 3.9 \\
\hline 18 & Precise formulation of vision and strategy & 0 & 0 & 2 & 4 & 4 & 10 & 3.6 \\
\hline & \multicolumn{8}{|l|}{ Project Management } \\
\hline 19 & Reliable contractual arrangement & 0 & 0 & 0 & 2 & 8 & 10 & 4.8 \\
\hline 20 & Decision making ability & 0 & 0 & 0 & 3 & 7 & 10 & 4.7 \\
\hline 21 & Management leadership skills & 0 & 0 & 0 & 4 & 6 & 10 & 4.6 \\
\hline 22 & Effective communication and co-ordination system & 0 & 0 & 0 & 4 & 6 & 10 & 4.6 \\
\hline 23 & Management commitment & 0 & 0 & 0 & 5 & 5 & 10 & 4.5 \\
\hline 24 & Appropriate organizational structure & 0 & 0 & 0 & 8 & 2 & 10 & 4.2 \\
\hline 25 & Strong \& reliable stakeholder consortium & 0 & 0 & 1 & 7 & 2 & 10 & 3.8 \\
\hline 26 & Effectiveness of human resource management & 0 & 0 & 2 & 6 & 2 & 10 & 3.4 \\
\hline 27 & Team motivation (rewards and incentives) & 0 & 0 & 3 & 3 & 4 & 10 & 3.2 \\
\hline 28 & Efficient supply chain management & 0 & 0 & 4 & 5 & 1 & 10 & 2.5 \\
\hline 29 & Contractor's experience \&reputation & 0 & 0 & 0 & 2 & 8 & 10 & 4.8 \\
\hline 30 & Contractor's reputation & 0 & 0 & 0 & 3 & 7 & 10 & 4.7 \\
\hline 31 & Contractor's financial strength & 0 & 0 & 0 & 4 & 6 & 10 & 4.6 \\
\hline 32 & Contractor's profitability margins & 0 & 0 & 0 & 6 & 4 & 10 & 4.4 \\
\hline \multirow[t]{2}{*}{33} & Use of new technology and automation & 0 & 0 & 5 & 3 & 2 & 10 & 2.2 \\
\hline & \multicolumn{8}{|l|}{ Project Conditions } \\
\hline 34 & Effective project monitoring \&control system & 0 & 0 & 0 & 3 & 7 & 10 & 4.7 \\
\hline 35 & Economic viability of the project & 0 & 0 & 0 & 7 & 3 & 10 & 4.3 \\
\hline 36 & Effective resource management & 0 & 0 & 0 & 7 & 3 & 10 & 4.3 \\
\hline 37 & Adequacy of planning and scheduling & 0 & 0 & 0 & 7 & 3 & 10 & 4.3 \\
\hline 38 & Project delivery system & 0 & 0 & 2 & 3 & 5 & 10 & 3.7 \\
\hline 39 & Project scope clarity & 0 & 0 & 2 & 4 & 4 & 10 & 3.6 \\
\hline 40 & Proper selection of the project type & 0 & 0 & 2 & 6 & 2 & 10 & 3.4 \\
\hline 41 & Project team experience & 0 & 0 & 3 & 4 & 3 & 10 & 3.1 \\
\hline 42 & Unforeseen conditions & 0 & 0 & 4 & 5 & 1 & 10 & 2.5 \\
\hline 43 & Weather conditions & 0 & 0 & 4 & 6 & 0 & 10 & 2.4 \\
\hline 44 & Adequate risk analysis & 0 & 0 & 6 & 3 & 1 & 10 & 1.7 \\
\hline
\end{tabular}

Table 4 depicts that in the domain, 'Role of Government', the attribute Government approval and involvement is the most relevant factor and is ranked first by the respondents. Similarly, accurate analysis of market and competition is at the first rank in the category 'Market Condition'. Timely release of funds to contractor, Design quality, Effective project briefing, and Client involvement in the projects are most relevant in the client capability domain. In the project management domain, various attributes are ranked most appropriate by the respondents, such as 'reliable contractual arrangement, Decision-making ability, management commitment, and contractor's experience and reputation. Finally, in 'project condition' domain; Effective project monitoring and control system and economic viability of the project are ranked most relevant by the respondents.

\section{CONCLUSION}

Public projects in Pakistan are facing many delays and conflicts. Therefore, there is a dire need to study the factors influencing the successful completion of public projects in Pakistan. This study reported that the role of the Government, client capability, and project management are major factors that play a vital role in achieving the success of any project. This study suggests that the Government can take preventive measures and device policies for public projects. Similarly, contractors and consultants can gain knowledge and prepare beforehand before bidding for any public projects.

\section{REFERENCES}

1. Qazi, Abroon, Abdulrahim Shamayleh, Sameh El-Sayegh, and Steven Formaneck. Prioritizing risks in sustainable construction projects using a risk matrix-based Monte Carlo Simulation approach, Sustainable Cities and Society 65:, 2021.

2. Taghipour, Mohammad, Nader Shamami, Ahad Lotfi, and M. S. Parvaei, Evaluating Project Planning and Control System in Multi-project Organizations under Fuzzy Data Approach Considering Resource Constraints (Case Study: Wind Tunnel Construction Project), Management 3, no. 1, pp. 29-46 2019.

3. Xiang, Wenwen, Ying Li, and Yongyi Shou. An empirical study of critical success factors of project governance in China. In 2013 IEEE International 
Sardar Ahsen et al., International Journal of Emerging Trends in Engineering Research, 9(10), October 2021, 1321 - 1326

Conference on Industrial Engineering and Engineering Management, pp. 405-409. IEEE, 2013.

4. Abas, Muhammad, Sikandar Bilal Khattak, Tufail Habib, and Uroosa Nadir. Assessment of critical risk and success factors in construction supply chain: a case of Pakistan, International Journal of Construction Management, pg.1-9, 2020.

5. Goel, Ashish, L. S. Ganesh, and Arshinder Kaur. Deductive content analysis of research on sustainable construction in India: current progress and future directions, Journal of Cleaner Production 226): pg. 142-158, 2019.

6. Farooqui, Rizwan, Syed Ahmed, and Sarosh Lodi. Assessment of Pakistani construction industry-current performance and the way forward, Journal for the advancement of performance information and value 1, no. 1, pg. 51-51, 2008.

7. Rockart, John Fralick. The changing role of the information systems executive: a critical success factors perspective, 1980.

8. Sanvido, Victor, Francois Grobler, Kevin Parfitt, Moris Guvenis, and Michael Coyle. Critical success factors for construction projects, Journal of construction engineering and management 118, no. 1, pg. 94-111, 1992.

9. Maqsoom, Ahsen, Muhammad Umer, Rafiq Muhammad Choudhry, Hafiz Zahoor, and Mubeenul Basharat, Factors Causing the Time Delay in Projects: Empirical Evidence from Pakistani Construction Industry, In ICCREM 2020: Intelligent Construction and Sustainable Buildings, pp. 611-621. Reston, VA: American Society of Civil Engineers, 2020.

10. Rashid, Y, Analysis of delay factors and their effects on construction projects, Management Science Letters 10, no. 6, pg. 1197-1204, 2020.

11. Rowlinson, S., and P. McDermott. Selection criteria in procurement systems: A guide to best practice, $E$ \& FN Spon, London, 1999.

12. Thompsen, Charles E, Program management: concepts and strategies for managing capital building programs, Construction Management Association of America, 2008.

13. Jaselskis, Edward J., and David B. Ashley. "Optimal allocation of project management resources for achieving success." Journal of construction engineering and management 117, no. 2, pg. 321-340, 1991.

14. Chua, David Kim Huat, Yue-Choong Kog, and Ping Kit Loh. Critical success factors for different project objectives, Journal of construction engineering and management 125, no. 3, pg. 142-150, 1999.

15. Cooke-Davies, Terry. The "real" success factors on projects, International journal of project management 20, no. 3, pg. 185-190, 2002.

16. Yang, Jing, Geoffrey Qiping Shen, Derek S. Drew, and Manfong Ho, Critical success factors for stakeholder management: Construction practitioners' perspectives, Journal of construction engineering and management 136, no. 7, pg. 778-786, 2010.

17. Park, Sung Ho, Whole life performance assessment: critical success factors, Journal of construction engineering and management 135, no. 11, pg. 1146-1161, 2009.

18. Zhang, Xueqing, Critical success factors for public-private partnerships in infrastructure development, Journal of construction engineering and management 131, no. 1, pg. 3-14, 2005.

19. Trinh, Minh Tri, and Yingbin Feng, Impact of project complexity on construction safety performance: Moderating role of resilient safety culture, Journal of construction engineering and management 146, no. 2, 2020. 